\title{
Cruz Salazar, TANia (2014), Las pieles que vestimos, corporeidad y prácticas de belleza en jóvenes chiapanecas. MéXICO, CESMECA-UNICACH/EL COLEGIO DE LA FronTERA SUR.
}

\author{
Fabio Alexis de Ganges-López
}

I a belleza, iqué es exactamente y por qué nos sentimos tan interesados en todo lo relacionado con esta palabra? Aquellos modelos que se nos presentan como "bellos", ison naturales o impuestos? ¿Será que incluso quienes fingen no pensar en este concepto utilizan algún tiempo en la mañana para arreglarse antes de salir al mundo? Este libro de Tania Cruz Salazar se presenta como un intento de responder a preguntas como: "¿Por qué la forma de los ojos, el olor corporal o los modos de arreglo personal han llegado a constituir estereotipos y modelos apreciados o degradados?" (p. 12). Al mismo tiempo, se erige como un análisis de tipos y concepciones de belleza que fenómenos como la globalización, el capitalismo tardío o la hegemonía occidental han dejado atrás por no corresponder a los patrones impuestos. Ahora priman los cuerpos ultradelgados, las caderas ínfimas, las piernas largas y la piel blanca.

El libro comienza con un recuerdo de la infancia. La autora asistía a la escuela Emiliano Zapata, en Tuxtla Gutiérrez, ataviada con muchos detalles coloridos: "iVestido de pastel! Corte cuadrado en la parte superior, mangas y pretina con dobleces, la falda muy plisada.
Regularmente eran vestidos blancos o floreados, con muchos detalles: encajes, cintillas y bieses" (p. 11). Los otros niños le decían "pinche chamula". Se nos recuerda que aquello que en otros lugares es solamente un gentilicio, en Chiapas deviene en insulto y atrae, semánticamente, connotaciones de suciedad, fealdad, pobreza, timidez o estupidez. De esta forma, una anécdota personal inicia una indagación sobre cómo las prácticas de belleza en un estado multicultural como Chiapas están teñidas de injusticias, marginaciones y concepciones absurdas acerca de qué es belleza y qué es fealdad.

La introducción propiamente dicha hace referencia a diversos antropólogos que han trabajado la cuestión del cuerpo desde diversos ángulos y a partir de prácticas de transformación, alteración y adaptación. Se menciona en especial la obra de André Lebreton, para quien los cuerpos modernos están radicalmente separados unos de otros, del cosmos y de sí mismos, debido a estructuras de tipo individualistas o, para decirlo con las palabras del mismo Lebreton, el cuerpo moderno es "el recinto objetivo de la soberanía del ego”. Estudiar las prácticas corporales es complicado porque, después de todo, el

Técnico académico titular "A" adscrito al Centro de Estudios Superiores de México y Centroamérica de la Universidad de Ciencias y Artes de Chiapas.

Recibida: 19 de septiembre de 2014 
antropólogo que se lo propone está inmerso en la prisión de su cuerpo. Antes las culturas estudiadas estaban alejadas en el espacio, pero actualmente existe con una nueva gama de etnografías multisituadas, de flujos y circuitos, de las emociones, virtuales, etcétera. Es decir:

Ante el observador minucioso, el cuerpo es una galería de entramados culturales que distinguen social, etaria y genéricamente a un sujeto. En este sentido, el cuerpo y las prácticas que lo definen resultan decisivos para estimular el pensamiento antropológico; el antropólogo se enfrenta primariamente a la apariencia física del otro, sus rasgos, su ornamentación, sus conductas, gestos y hábitos, es decir, a un conjunto de prácticas que expresan un aprendizaje permanente en el que, sin embargo, existe un amplio espacio de agencia, pues los sujetos expresan siempre una intención consciente de 'habitar el cuerpo' de manera peculiar y distintiva, mediante la identificación con múltiples cosmovisiones, representaciones y discursos (p. 20).

Prosigue el texto con un repaso sucinto de las transformaciones en las prácticas corporales orientadas al arreglo y embellecimiento de la persona, desde la antigüedad hasta nuestros días; el eje analítico enfatiza el proceso de ocultamiento y descubrimiento de la "intimidad" corporal que en la Edad Media y en la época posmoderna son diametralmente opuestos. Por ejemplo, las nuevas tecnologías hoy en día provocan que los cuerpos estén cada vez más alejados aunque presentes de modo virtual, mientras que en la Edad Media los cuerpos estaban unidos en el mismo tiempo y espacio. La tragedia insinuada con esta lectura es que se ha dejado de lado la necesidad de estar junto al cuerpo del otro para sentir placer.

Por otro lado, el apartado que recorre una parte histórica de la belleza occidental hegemónica recuerda los libros ilustrados de Umberto Eco, Historia de labelleza e Historia de la fealdad, pues nos permite asomarnos a un mundo fascinante en el que todas las épocas, mujeres y hombres han intentado mejorar su apariencia con muy diversos métodos que implican, por otro lado, desde modificaciones permanentes como los tatuajes, hasta el delineamiento de cejas y el cuidado de la piel. En ese sentido, es curiosa la anécdota de la reina Cleopatra bañándose en leche de burra o las prácticas de los hombres en la antigua Grecia para mantener "una mente sana en un cuerpo sano". Llama la atención el modelo de belleza posmoderno que, a decir de la autora, es el estereotipo actual:

El paradigma de la cintura pequeña y el vientre plano insertaron a las mujeres en una dinámica de trabajo constante. El vientre de las mujeres se convirtió en objeto de apreciación, no sólo masculina sino a nivel general. El cuerpo de las mujeres ha sido utilizado para modelar ropa escotada que insinúa un cuerpo delgado y trabajado con sólo enseñar un vientre sin grasa. Mostrar un vientre sin lonjas llama la atención y es altamente valorado en estos días. Arreglar la apariencia para la mujer significa más que nunca arreglar el cuerpo, ya no sólo mediante prácticas de perfeccionamiento gradual - la aplicación de cremas para broncear o para aclarar la piel, el uso de pinzas, de ceras o de máquinas depiladoras para extraer el vello corporal - sino que "arreglarlo" ahora expresa la idea de la confección mediante prácticas de alteración radical: la liposucción, el implante de senos, la eliminación de arrugas con rayos láser, con la inyección de bótox o colágeno o la cirugía cosmética de todo tipo (p. 40).

En el primer capítulo la autora usa el concepto "heterotopía" de Michel Foucault — mencionado en el ensayo "Espacios diferentes", uno de los últimos del lúcido filósofo e historiador francés - para referirse a un espacio en el que coexisten acciones y nociones temporales, con lógicas y manifestaciones culturales diversas. En ese sentido, la ciudad de San Cristóbal es vista como una heterotopía, lo cual es de gran importancia para estudiar actitudes de grupos sociales diversos que conviven en un mismo espacio. "Entender la ciudad de San Cristóbal de Las Casas como una heterotopía permite estudiar las prácticas de belleza en relación con las concepciones, representaciones y discursos del espacio social, lo que constituye 
la relación sujeto-corporeidad" (p. 59). Además, esta noción de heterotopía se puede unir a otra de Bourdieu para sugerir tanto el "campo ecuménico" o de la globalización, como el "campo cotidiano", con lógicas temporales diferentes. En ese sentido se dan diferentes discursos acerca de lo que la belleza significa para diferentes personas: el tradicionalista, el médico y el religioso. Esto es de gran importancia porque nos muestra que ningún pronunciamiento acerca del cuerpo, la belleza o la manera en que uno se ve o es visto por los otros resulta inocente o natural; al contrario, todo, como el mismo Foucault nos ha mostrado en sus libros, se ha construido en algún momento y de alguna manera. Valiosas en este sentido son las entrevistas en las que las jóvenes o las personas cercanas a ellas revelan lo que piensan acerca de la belleza y ven como algo natural y sin vuelta de hoja, por más racista, ofensivo o ridículo que parezca.

Una de las cuestiones más interesantes del libro es la contraposición de los diferentes discursos que se han propagado en San Cristóbal acerca del cuerpo. Contrasta sobremanera la visión indígena, tan apegada a la tierra y a la luna, con la occidental, dualista y que se origina en la división que hizo Descartes entre mente y cuerpo. A esto hay que agregar un discurso religioso compartido por ambas culturas. De esta forma es posible descubrir diferentes maneras de percibir el propio cuerpo y cómo este es visto por los otros - de nuevo recordando que, según Foucault, el espejo es la heterotopía más básicaen lo que declaran las entrevistadas, mezclándose incluso discursos distintos, especialmente cuando las mujeres indígenas han migrado a la ciudad y adquieren algunas de las costumbres urbanas a las que no tienen acceso en sus comunidades, como tener relaciones de amistad o noviazgo.

Los planteamientos de la autora cuestionan los modelos hegemónicos de belleza y nos sugieren ver lo que, a nuestro alrededor, se impone como un esquema cuadrado y elitista el cual, más que disfrutarlo, lo sufrimos tanto varones como mujeres. No sólo las extremas concepciones de la moda, con cuerpos tan delgados, resultan imposibles de lograr para la mayoría de las mujeres - lo que les provoca incluso esas enfermedades de la modernidad, la bulimia y la anorexia-, sino que los varones buscan algo que realmente no existe de forma pura en el mundo real. En ese sentido, es fascinante adentrarse en las concepciones de las propias implicadas, es decir, de las chicas indígenas y mestizas que han sido entrevistadas por la autora, para mostrar un mapa de cómo se ven a ellas mismas y cómo ven a las otras. El resultado son cuadros que tienen un alto grado de autodenigración, racismo y elitismo, y muy poca objetividad, ya que:

En una sociedad en la que gran parte de la población femenina cuenta con un fenotipo distinto al del modelo hegemónico de la belleza y que además convive en un ámbito de racismo cultural y de clase, las relaciones son acentuadamente asimétricas. Es prioritario entonces problematizar el modo en que las representaciones del indio y de la mujer van delineando las formas en que las jóvenes chiapanecas se embellecen. ¿Cuáles son estas prácticas que tanto indígenas como mestizas llevan a cabo para alcanzar el modelo hegemónico de la belleza? ¿A qué representaciones apelan en este trayecto? (p. 98).

Más adelante se cuestiona la "pureza" y la supuesta estabilidad de la belleza, que en realidad cambia constantemente no sólo de una época a otra, sino respecto de la condición social e incluso de los caprichos o imposiciones que se hacen sobre las mujeres, obligadas a mostrar un rostro y un cuerpo acordes con la mentalidad de una sociedad machista y occidental:

Las mujeres mexicanas, indígenas y mestizas, de acuerdo con sus identidades culturales específicas, deconstruyen los modelos hegemónicos de belleza $\mathrm{y}$ viven su cuerpo como un proyecto permanente de afirmación genérica que implica tensión y adaptación cultural; al interpretar tales modelos, despliegan un conjunto de prácticas de belleza que funcionan como tecnologías de género, es decir, como un conjunto de técnicas y procedimientos empleados para llegar a ser un tipo de mujer (p. 47). 
En un movimiento de lo general a lo particular, la autora aborda las prácticas de belleza en las jóvenes indígenas y no indígenas en la ciudad de San Cristóbal de Las Casas, como el arreglo personal, la modificación habitual, el perfeccionamiento corporal y el adorno permanente. Sus herramientas de investigación van desde los cuestionarios, a la entrevista, el diario de campo, la biografía, fuentes hemerográficas y recortes o dibujos. En cuanto a la elección de la muestra, se explica desde el capítulo uno:

La definición de un grupo de mujeres con diferentes características étnicas y sociales fue constituida por doce jóvenes. Seis indígenas y seis mestizas. Del grupo de indígenas, todas ellas provenían de familias de migrantes, cuatro son tzotziles y dos tzeltales, en correspondencia con la mayoría y minoría étnica de San Cristóbal. De las seis mujeres mestizas, cuatro son sancristobalenses y dos tuxtlecas; todas viven en San Cristóbal. Para cruzar datos sobre el imaginario colectivo que se tiene del "ser mujer", fue necesario no sóloindagar sobre la visión femeninamestiza eindígena entrevistando a las doce jóvenes, sino a la contraparte masculina, por lo que entrevisté a diez jóvenes varones que tenían una relación fraternal, familiar o amorosa con las jóvenes entrevistadas (p. 52).

En el último apartado, titulado "Atavíos", analiza con detalle las prácticas de discriminación que ocurren en un espacio como San Cristóbal de Las Casas, en donde confluyen diversos grupos étnicos, especialmente indígenas y mestizos. En general son las mujeres mestizas quienes discriminan a las indígenas, adjudicándoles una gran cantidad de expresiones denigrantes, como "nacas" o "chamulas". Cada sección de esta última parte tiene un subtítulo irónico respecto a las prácticas discriminatorias a las que se refiere el título: "Pestañas de paraguas, pestañas de indios", "Salió toda emperifollada: prácticas ornamentales" o "Aunque la mona se vista de seda, mona se queda". Si antes ya se había expuesto la discriminación hacia los indígenas con un texto de Rosario Castellanos, el siguiente texto es aún más incisivo en dichos señalamientos:
¿Cómola representación del indio ha sido alimentada a través del tiempo? Hoy en día al cuerpo de las indígenas le corresponde una serie de cualidades que han configurado "la verdad" sobre la indianidad o, si se prefiere, sobre el indio, esa representación de la que ha venido hablando. Ésta se construye con imágenes asociadas a la suciedad, cuando se afirma que todos los indígenas 'son apestosos'; a la ignorancia, cuando se presume que 'no entienden'; a la fuerza bruta, cuando se asegura que 'son violentos'; a la incapacidad económica quefomenta expresiones paternalistas como la de pensar que 'son pobrecitos', y a la supuesta incapacidad intelectual, entendida como la falta de agilidad en las acciones, cuando se dice que son 'lentos' (p. 100).

Las conclusiones hablan de la apropiación, por parte de un grupo de mestizas de clase social alta o media, de textiles, bordados y ornamentos hechos por grupos de indígenas. Las primeras no les otorgan una valoración auténtica y solamente ven estos elementos como cuestiones de folclore; probablemente, la peor manera de despreciar una cultura fingiendo hacer lo contrario.

Un estudio es valioso cuando deja preguntas que esperan futuras respuestas, cuando analiza un tema que se da por hecho, cuando nos muestra que, por el contrario, nada es fijo y todo es construido $\mathrm{y}$, sobre todo, cuando abre los ojos a nuevas realidades. En ese sentido, uno ve la belleza de manera diferente después de la lectura de este libro, especialmente con ayuda de imágenes, por demás hermosas, de reconocidos fotógrafos como Carlos Dardón, Efraín Ascencio, Abraham Gómez y Eduardo Laborda. En todo caso, si hubiera algo que reprochar sería el que no haya hecho algunas preguntas más incisivas, eventualmente, a alguna de las entrevistadas. ¿Pero acaso era eso posible? Regresando al texto de Foucault que habla de la heterotopía, estamos condenados a recrearnos constantemente en un imaginario espejo social. Falta ver si en algunos años las prácticas de belleza se transformarán aún más, y si este estudio se constituirá en una puerta para futuras indagaciones, incluso, por qué no, entre los varones. 